\title{
Development of a System Model for Determining Optimal Personnel Interaction Strategy in a Production Industry
}

\author{
B. Kareem ${ }^{*}$ a and A. Adekiigbe ${ }^{b}$ \\ a B. Kareem, Department of Mechanical Engineering, Federal University of Technology, Akure, Nigeria. \\ ${ }^{b}$ A. Adekiigbe, Department of Mechanical Engineering Technology, Osun State Polytechnic, Iree, Nigeria.
}

Received 29 July 2013; Accepted 9 June 2016

\begin{abstract}
Manufacturing organizations have become more complex in recent time as a result of technological advances. Communication among production workers operating in an environment marked by increased organizational complexity may require planning for the economically appropriate selection of network channels/media with enhanced productivity. This paper examines traditional and modern communication channels (media) and their comparative advantages over one another in their adoption in manufacturing organizations. In this framework, six media (human messengers, mobile-phones, intranet, fixed-internet, mobile-internet, and private branch exchange $[\mathrm{PBX}]$ phone systems) were subjected to analyses using five identified network patterns (all-channel, chain, Y, wheel, and circle) of interactions in manufacturing organizations. Costs, benefits, and the utility of the channels were integrated into the model and utilized to determine the most sustainable media that could enhance productivity in industry. The developed model was implemented using expert data/information collected from the plastic production industry. The results of an availability assessment showed that the enhancement of productivity could be fully achieved by utilizing mobile phones and internet networks, but when considering overall utility, only mobile phones could bring about the desired productivity with 0.59 probability. The findings suggest that the system developed is robust in revealing how productivity might be affected by means of communication among industrial workers.
\end{abstract}

Keywords: Communication, Channels, Personnel, Productivity, Utility.

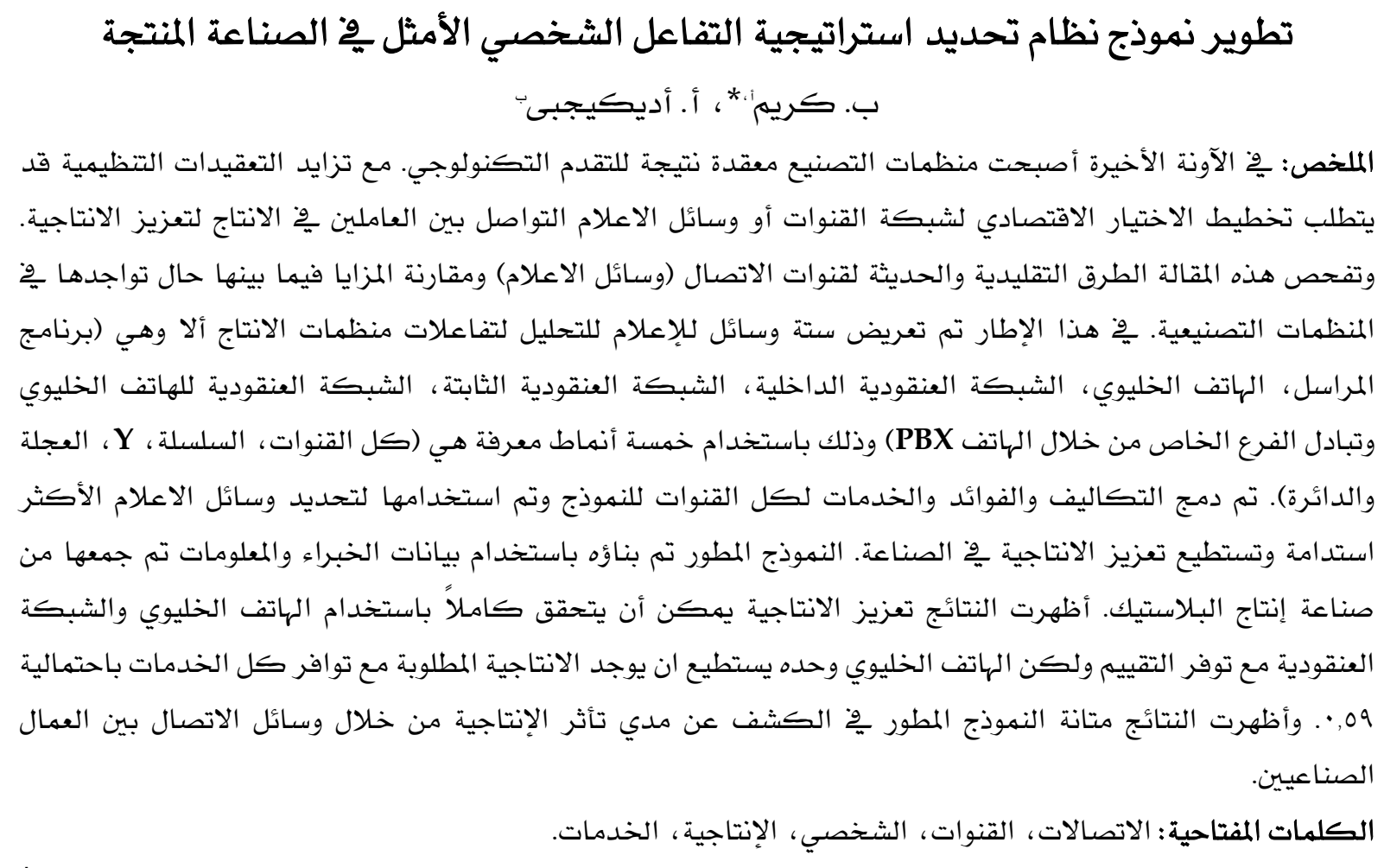

\footnotetext{
* Corresponding author's e-mail: bkareem@futa.edu.ng
} 


\section{Introduction}

The transformation of production resources to useful goods and services requires effective interaction among the principal resources, namely manpower, material, and machinery (Drucker 2002). People in organizations need to communicate within and outside of those settings for effective coordination of production processes and service delivery (Kleinbaum et al. 2008). Interaction (communication, contact, interface, dealings, relations, collaboration) is the process of sharing ideas, information, and messages with others in a particular time and place (Kleinbaum et al. 2008). Communication may be written or spoken, or expressed in some other way. In another categorization, communication may be nonverbal or verbal. Nonverbal communication includes facial expressions, body language, or gestures. Verbal and visual communication may be in the form of images or pictures (painting, photography, video, or film) while telephone calls, electronic mail, cable television, satellite broadcasts, direct conversation, etc. are examples of verbal or electronic communication (Balschbach et al. 1998; Payne et al. 1996). Contributions of nonverbal communication system in terms of cost and effectiveness to the production process are difficult to measure because of the seeming intangibility of the system (Nucci et al. 2013). However, interaction by means of verbal and electronic communication systems is quantifiable, and its effectiveness to the production process (productivity) is measurable (Balschbach et al. 1998; Nucci et al. 2013; Payne et al. 1996) using appropriate decision tools (Saaty 1990). In the current study, a system model is developed for sustainable personnel interaction in a production industry by considering the relative utility of communication channels with the objective of achieving effective service delivery in the organization.

Interaction in the production industry should be based on a pre-determined design with the target of improving output capacity or enhancing goodwill (Gurbaxani and Plice 2004). Advanced technology has created many communication tools that could be necessary and useful in the improvement process (Nagy 2013). Companies have a choice to make among various communication channels available in order to sustain their competitiveness (Gurbaxani and Plice 2004). It is possible that making wise choices in communication channels might improve the agility and efficiency of an industrial system (Biggiero 1999; Stohl 1995; Wada et al. 2013; Yates et al. 1999).

Communication/interaction models have been used throughout history as a means of analyzing the components and structures of effective communication in the industry (Opperman 2013; Shannon 1948). Models that are well known and widespread in the literature (Feital et al. 2013; Nagy 2013; Payne et al. 1996; Shannon 1948) for information/ communication technology (ICT)-based cost estimation and benefit in organization are the total cost of ownership model (TCO) which deals with all costs associated in the lifecycle of any capital investment in hardware or software, from acquisition to disposal (Lievrouw 2008; Nagy 2013). The Jikes RVM Adaptive Optimization System (Shannon 1948) attempted to evaluate the break-even point for each action using an online competitive algorithm (Zhao et al. 2013). It relies on an analytic model to estimate the costs and benefits of each selective recompilation action, and evaluates the best actions according to the model predictions online. The enterprise resource planning (ERP) system established and implemented administrative software systems that are organizational based. The ERP software systems provided are expensive and have long-term financial and human resources consequences (Opperman 2013). The business impact analysis (BIA) (Feital et al. 2013) determined how far to go in protecting the functions of the people, information, and equipment in an organization in order to sustain their reliability (Kareem 2015). The quantitative risk model (QRM) (Nohria and Eccles 1992) was used to analyze expected interaction losses over a pre-determined period (Sooksumrarn and Krairiksh 2013). The generalized cost consequence (GCC) (Nohria and Ghoshal 1997; Payne et al. 1996) model estimates the total cost of interaction outages as a function of time after an event. The major diagnostic category model (MDC) (Kleinbaum et al. 2008) helps to relay information that enable the determination of resources that experience highly severe or very frequent losses in production organizations.

In the stated models system, interaction was determined using separate criteria based on lines of authority (line, functional, modified, hierarchical, matrix, flat, and combination) 
(Central Intelligence Agency [CIA] 2011; Jaques 1998; Urwick 1943; Urwick 1974), patterns of interaction (circle, Y, chain, wheel and allchannel) (Payne 1996), or the channels of transmission (human messengers, telephones, face-to-face, meetings, memorandum, formal report, teleconferencing, intranet, fixedinternet, mobile internet, PBX phone system (Froehle 2006; Kuboye et al. 2009; Larkin and Larkin 2005; Payne 1996; Stohl 1995). Many of these studies were carried out theoretically (Bhattacharjee 2007; Biggiero 1999; Mackenzie 1978; Urwick 1974). There is a need for integrating interaction channels and lines of authority into a production system in order to arrive at a realizable and practical system model useful for the sustenance of productivity and effective service delivery.

The identified channels/media of telecommunications utilized in Nigerian production industries-MTN, Zain, Glo Mobile, Visafone, Multilinks, Starcomms, Zoom, and Etisalat-control the GSM market (Kareem 2014; NDB 2007). Past studies (Kuboye et al. 2009; Olokede 2009) have found some of these channels to be unreliable and exhibit random failures similar to other mobile systems (Kareem 2015). The effects of utilizing any of these communication channels / networks on productivity in the industry have not been quantitatively addressed (Mtega and Msungu 2013; Nyambo and Ligate 2013). Previous studies failed to consider the cost benefit and utility of different ICT channels in industry (Cevasco and Marmolejo 2013; Hurley 2008; Jackson et al. 2012; Larkin and Larkin 2005; Li et al. 2013; Lu and $\mathrm{Yu}$ 2012). The contribution of this study to the literature is to propose the integration of communication channels and personnel interactions into lines of authority. Additionally, the study aims to highlight the responsibilities of a production organisation in minimizing lifecycle costs and maximize the benefits and utility of the selected channels with a target of improving productivity and service delivery.

The practical implementation of an integrated system for determining optimal interaction channel(s) in a production industry will be carried out. The study will be extended to cost benefit and utility analyses of the media. A cost-benefit analysis involves weighing the total expected costs against the total expected benefits of one communication channel /medium over the others (Bhattacharjee 2007) in order to select the most profitable option. A discount rate will be used to compute all relevant future costs and benefits in present value terms. Utility is an alternative measure based on the non-monetary benefit used to express the relative satisfaction of personnel (values) with the communication/interaction media/channels under consideration. Utilities of affordability, dependability, maintainability, portability, flexibility, and usability of service equipment have been explained in the literature (Adam et al. 1995; Bhattacharjee 2007). For this study, only attributes based on affordability (acquisition, development, and operations) and usability (performance, availability, and quality) will be considered because of the low capital outlay and technicalknow-how of the production industries in a developing economy. A technique based on the analytical hierarchy process (AHP) was found to be promising (Finnie et al. 1993; Saaty 2008) for analyzing the stated attributes because it helped set priorities and the likelihood of arriving at the most optimal decision under complex qualitative and quantitative characteristics (Saaty 1990).

\section{Model Formulation}

This section provides modelling parameters, relationships among the parameters, a modelling strategy/framework, and the implementation of the model with a case study.

\subsection{Modelling Parameters and Objectives}

In developing the model, the parameters considered in regards to the production industry include communication channels/media in use, the number of personnel involved, pattern(s) of interaction, and the cost, benefit and utility of the channels/media utilized. Communication channels considered in the model were the use of traditional human messengers, mobile phones, the intranet, fixed internet, mobile internet, and a PBX phone system. The patterns of communication/interaction utilized were chain, Y, wheel, circle, and all-channels (Kareem 2014). The objective was to obtain (choose) communication channel(s) for the industry with minimum operation costs and maximum benefits and utility. The number of personnel involved was the major constraint besides the number of communication patterns and channels utilised. 

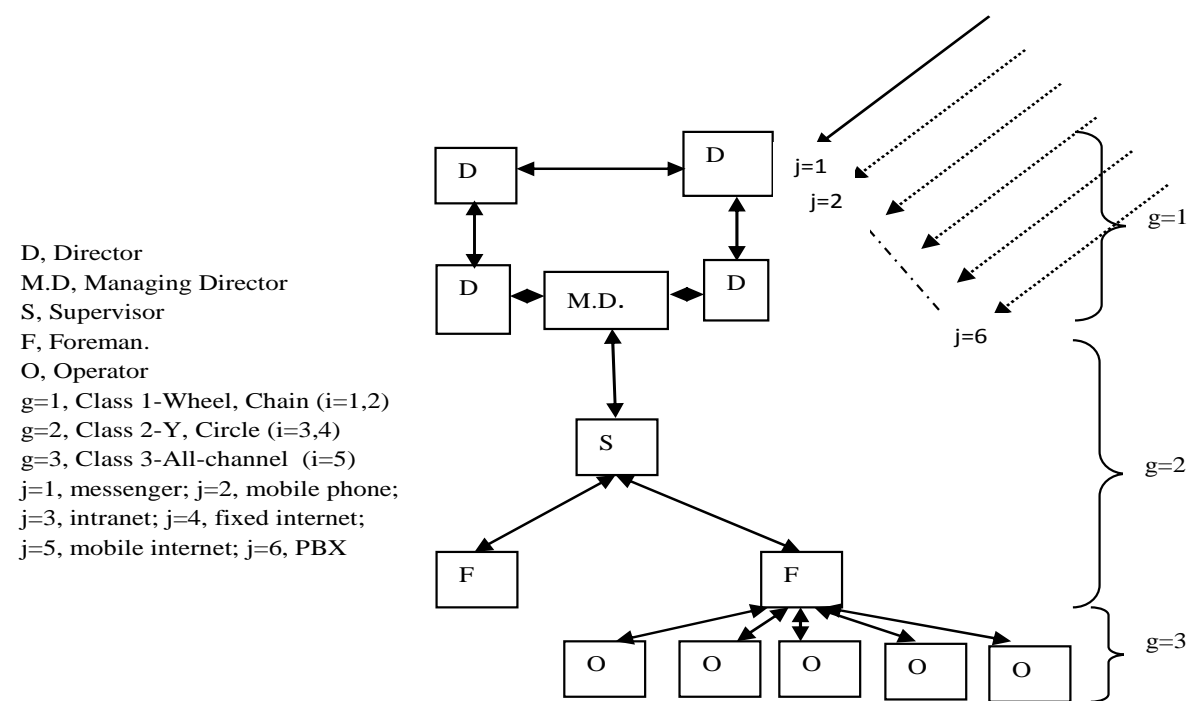

Figure 1. Interaction pattern, authority and responsibility relationships.

\subsection{Modelling Parameter Relationships}

Relationships that exist among the model parameters appear in Fig. 1. It consists of channels $\mathrm{j}(j=1,2 \ldots 6)$. Each channel $j$ option could be utilized by personnel numbering $\rho$ using interaction / communication network pattern(s) i ( $i=1,2$, $\ldots, 5)$ of class $g(g=1,2,3)$. The total number of interactions at class $\mathrm{g}$ when using channel $j$ is $\mathrm{N}_{\mathrm{gi}}^{\mathrm{j}}$ while the total number of interactions at all classes considered is $\mathrm{N}_{\mathrm{T}}$. This is integrated into the lines of authority and responsibility of the production organization in order to minimize lifecycle costs and maximize the benefits and utility of the selected channels $j$ in the industry.

\subsection{Modelling Strategy/Framework}

The generalized interaction relationship based on the authority of personnel and their responsibility (Kareem 2014; Payne et al. 1996) in the manufacturing organizations is expressed as Eqn. (1).

$$
\mathrm{N}^{1}=\rho(\rho=1)
$$

where, $\mathrm{N}^{1}$, is the total number of interactions and $\rho$ is the number of personnel. Eqn. (1) shows no restriction in interaction. Practically speaking, this is not always possible as effective operation may require confidential information among the top management levels such as directors (Fig. 1). The effectiveness of information is weaker down the ladder. Ordinarily, there must be a higher level of confidentiality in the information received by managers from managing directors (first class, $g=1$ ) than in the information received by the supervisors from a manager (second class, $g=$ 2). Information becomes weakest at the production floor (third class, $g=3$ ). Based on the stated characteristics, Eq. (1) was modified to take care of three identified categories of interactions, namely direct single (information flows from the managing director to the manager), cross (from manager to supervisors), and direct groups (among supervisors, foremen, or operators) (Fig. 1). The cumulative sum of interactions at various levels can be expressed as Eqn. (2):

$$
\mathrm{N}_{\mathrm{T}}=\sum_{\mathrm{i}}^{5} \mathrm{~N}_{\mathrm{gi}}^{\mathrm{j}}
$$

where, $\mathrm{N}_{\mathrm{T}}$ the total number of interactions in the workplace, $N_{g_{i}}^{j}$ is the total number of interactions in a class or category, $g(g=1,2,3)$ is the collection of network pattern, $i,(i=1,2, \ldots, 5)$, using a communication channel, $j,(j=1,2, \ldots, 6)$. 
The first class category $(g=1)$ was made up of the network pattern wheel and chain, $i,(i=1,2)$. The second class category $(g=2)$ consisted of network pattern $\mathrm{Y}$ and circle $i,(i=3,4)$ while the third category $(g=3)$ comprised an all-channel network pattern $i,(i=5)$. The communication channels, $j$, considered were messengers $(j=1)$, mobile phone $(j=2)$, intranet $(j=3)$, fixed internet $(j=4)$, mobile internet $(j=5)$ and $\operatorname{PBX}(j=$ 6).

\subsection{Cost and Benefit Model}

The lifecycle cost was calculated for the interaction channels $J$ with reference to data from information technology (IT) vendors (Kareem 2014, NDB 2007) as:

$$
\mathrm{C}_{\mathrm{C}}^{\mathrm{j}}={ }_{\mathrm{C}=1}^{\mathrm{k}} \mathrm{C}_{\mathrm{C}}^{\mathrm{j}}
$$

where

$\mathrm{C}_{\mathrm{C}^{\prime}}^{\mathrm{j}}$ is the total life cycle costs of using communication channel, $j$ per unit of time. $C$, is the counter for elemental costs of the life cycle per unit of time $(c=1,2, \ldots, k)$ for a particular communication channel, $j$. The life cycle cost elements comprised initial setup cost, acquisition cost, development cost, operations cost, and maintenance cost.

The cost of interaction, $\mathrm{C}_{\mathrm{T}}^{\mathrm{j}}$, was estimated as the product of lifecycle cost, $C_{C}^{j}$, the total number of interactions, $\mathrm{N}_{\mathrm{T}}$, and the time taken, $t$. The optimal channel, $j$, corresponds to the minimum (min.) of the function in Eq. (4).

$C_{T}^{j}=\min . j\left[C_{c}^{j} t \sum_{i}^{5} N_{g_{i}}^{j}\right]$

The benefit function for the interaction channels was estimated as

$B_{B}^{j}=\sum_{b=1}^{q} B_{b}^{j}$

$B_{B}^{j}$, is the total benefit cost of using communication channel, $\mathrm{j}$, per unit of time, $b$, is the counter for elemental benefits/savings per unit of time $(b=1,2 \ldots q)$ for a particular communication channel, $j$, as utilized by the industry. The benefits/savings comprised overhead, productivity increase, maintenance cost, and operations cost savings.

The total benefit of each interaction channel in term of cost savings is:

$B_{T}^{j}=B_{B}^{j} \sum_{i=1}^{5} N_{g_{i}}^{j}$

The optimal channel, $j$, was obtained corresponding to the maximum (max.) benefit and expressed as:

$B_{T}^{j}=\max \cdot j\left[B_{B}^{j} \sum_{i=1}^{5} N_{g_{i}}^{j}\right]$

where, $\mathrm{B}_{\mathrm{T}}^{\mathrm{j}}$ is the total benefit of interaction.

The costs and benefits were spread over a period of three years, the time period that was considered one lifecycle, for the interaction channels with a discount rate of $8.75 \%$ (Kareem, 2014). The net present value (NPV) of benefits-costs $(B C)$ was calculated as:

$\mathrm{NPV}=\mathrm{PVB}-\mathrm{PVC}$

The comparison of the overall costs and benefits and the benefit-to-cost ratio $(B C R)$ was carried out using Eq. (9):

$\mathrm{BCR}=\frac{\mathrm{DB}}{\mathrm{DC}}$

$P V C$ represents the present value of cost, which is $C_{T}^{j} * D R$,

$P V B$ represents the present value of benefit, which is $B_{T}^{j} * D R$,

$D B$ represents the cumulative discounted benefits,

$D C$ represents the cumulative discounted costs, $D R$ represents discount rate, which is a measure of $1 /(1+r)^{m}$ (Kareem 2014),

$r$ is the discounted factor, and $m$ is the channel life cycle.

The channel(s) with the highest BCR was recommended for improved productivity in the industry. Any channel having a $B C R$ of less than one could lead to shortages in the organization. Post optimality based on utility analysis would assist in determining whether he communication channel(s) could withstand the test of time under usage. 


\subsection{Network Utility Performance Analysis}

In order to further ascertain the optimality of the network channel(s) from the benefit-cost ratio $(B C R)$ outcomes, utility performance analysis was carried out. In this sense, the utility of affordability and a usability analysis were carried out to take care of the low-capital nature of the industries in developing economies. In this process, a BCR comparison of the channels was converted to their respective utility values. The objective was to select channel(s) with maximum utility value. The stated objective was achieved by using an
AHP (Saaty 1990) with an additive utility function (Vargas 1990).

\subsubsection{Hierarchy Process Model Application} Analytical Process

The relative specific weights for the communication channels were calculated by the AHP (Saaty 1990; Vargas 1990). The computations employed by AHP can be decomposed into the following six steps:

- A pair-wise comparison matrix $A^{j}$ was formed with the communication channels considered.
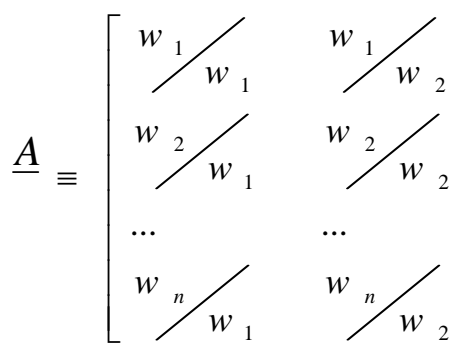

where each $w$ is the corresponding weight (or importance level) of each individual channel, and each entry within the matrix represents the relative weight ratio between two channels.

- The gathered data on level of utility/importance of the channels from industrial experts were converted to the fractional ratio from which the average weight of each channel was calculated in a matrix format.

- The matrix product was formed by multiplying, element by element, each row of the first vector, $\underline{\mathrm{A}}_{1, \mathrm{j}=1,2, \ldots,}\left(w_{1} / w_{n=1,2, \ldots, n}\right)$ by corresponding elements of the second vector, $w_{j=1,2, \ldots . n}$, and adding. Thus, the first element of the product would be:

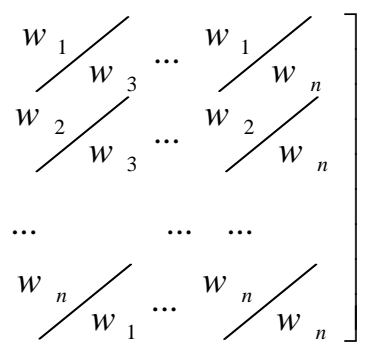

$\left(w_{1} / w_{1}\right)^{*} w_{1}+\left(w_{1} / w_{2}\right)^{*} w_{2}+\ldots+$

$\left(w_{1} / w_{n}\right)^{*} w_{n}=n w_{1}$.

Similarly, for the second element, the product would be

$\left(w_{2} / w_{1}\right)^{*} w_{2}+\left(w_{2} / w_{2}\right)^{*} w_{2}+\ldots . .+$

$\left(w_{2} / w_{n}\right)^{*} w_{n}=n w_{n}$

Thus, the resulting vector for $n^{\text {th }}$ element is $n w_{n}$.

- The eigenvector of matrix $\underline{\mathrm{A}}$ was then computed.

- The eigenvector result was standardized by summing up the rows and row totals (this is the first approximation of the eigenvector). 


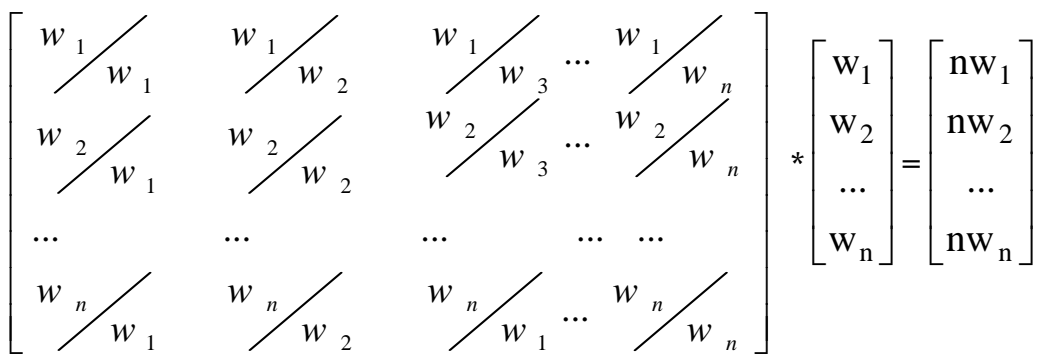

$\underline{A} * \underline{w}=n \underline{w}$

- The system was finally normalized by reiterating steps iii and iv in order to arrive at a consistent matrix with the following features.

$a_{i k} a_{k j}=a_{i j}$ for all $i, j$.

In forming the matrix, a comparison of the two attributes was made to take any of the following values: equally important-1; moderately important-2; strongly important-3; very strongly important-4; and extremely important-5.

Based on the stated model, a comparison of the channels $(j)$ was carried out on the basis of the level of utility attributes (affordability and usability), with additive utility function assigned the value of 0 and 1 to the worst and best conceivable outcomes, respectively. Affordability was measured in monetary terms while usability was measured non-monetarily (subjectively) (Saaty 2008; Vargas 1990).

\subsubsection{Computation of Weighted Utility}

The weighted utility function (Saaty 1990) $\mathrm{U}_{\mathrm{n}}^{\mathrm{j}}$ (affordability, $a$ ) for the three sub-attributes $(n)$ of acquisition $(n=1)$, development $(n=2)$ and operations $(n=3)$ was represented by the equation

$U_{n_{a}}^{j}=\sum_{n=1}^{3} W_{n}^{a} U_{j}^{a}(j=1,2, \ldots, 6)$

where, $j$ represents the available interaction channel options.

Similarly, usability in which the three attributes $(n)$ were performance $(n=1)$, availability $(n=2)$ and quality $(n=3)$ was also obtained using the weighted utility function (for usability, s) $\mathrm{U}_{\mathrm{n}_{\mathrm{s}}}^{\mathrm{j}}$ and was represented as
$U_{n_{s}}^{j}=\sum_{n=1}^{3} W_{n}^{s} U_{j}^{s}(j=1,2, \ldots, 6)$

The cost-benefit ratios across different attributes of affordability and then usability were converted into individual utilities as follows:

Utility $j(B C R)=(B C R-$ Worst Value $) /$

(Best Value - Worst Value)

Here, subscript $j$ is the channels for which utility is to be calculated and BCR is the value for that attribute or attribute of usability. The worst value is the lowest BCR value, and the best value is the highest $B C R$ value. A combination of utility by affordability (a) and usability (s) $U_{n_{0}}^{j}$ was used to estimate the overall utility value as:

$U_{n_{o}}^{j}=\left(U_{n_{a}}^{j}+U_{n_{s}}^{j}\right) / 2$

Based on the outcome of Eq. (18) (utility of affordability and usability), the interaction channel(s) with the highest overall utility value $U_{n}^{i_{0}^{*}}$ will be recommended as the communication network. That is,

$U_{n_{o}}^{j *}=\max \cdot j\left[\left(U_{n_{a}}^{j}+U_{n_{s}}^{j}\right) / 2\right]$

\section{System Model Implementation}

An application of the system was carried out with a plastic production industry in Osogbo, Nigeria, running within a capital base of millions of Nigerian naira ( $\mathrm{N}$ is the symbol for the Nigerian currency, and one US dollar is equivalent to approximately N170). The company manufactures polyvinal chloride (PVC) pipes, polyethylene (PE) pipes, fittings, 
Table 1. Interaction data from the plastic industry.

\begin{tabular}{lll}
\hline S/N & \multicolumn{1}{c}{ Interaction Information } & \multicolumn{1}{c}{ Description } \\
\hline 1 & Organizational structure & Hierarchical authority \\
2 & Interaction patterns & Circle, chain, Y, wheel and all-channel \\
3 & Interaction flow & Downward, upward, \& lateral \\
4 & Interaction channel & Memoranda, meetings \& face-to-face \\
5 & Average production rate (units/year) & $1,152,000$ \\
6 & Average production income rate (N/year) & $921,600,000$ \\
7 & Staff strength & 75 \\
8 & Average salary and wages (N/year) & $40,088,000$ \\
9 & Messengers (no.) & 16 \\
10 & Average salary and wages (16 messengers) & $3,063,300$ \\
& including food contributions, transportation & \\
11 & costs, social costs, health cost (N/year) & $841,088,000$ \\
12 & Average production input (N/year) & $400,000,000$ \\
13 & Average fixed capital (N/year) & $400,000,000$ \\
14 & Pverage raw materials costs (N/year) & $1,000,000$ \\
\hline
\end{tabular}

and other plastic products. Data were obtained on the organizational structures, including the nature of the division of labor, the type of hierarchical authority, and job descriptions. Job descriptions included information about whether jobs were centralized or decentralized. Data were also collected on whether the organization was divisional, functional, matrixed, or networked, and on the type of reporting relationships or reward structure that existed, channels and media of interaction, and workforce size. It was noted whether industries utilized messengers to transfer messages from one department/unit to another, and whether the company would like to increase its productivity by finding alternative ways of message transfer by using other means besides messengers. The data collected were tabulated and entered into Table 1. The organization chart, including personnel interactions and lines of authority and responsibility to the company, was similar to one presented in Fig. 1.

The implementation process was carried out in steps. First, interaction levels of the three classes (i.e. first, second, and third) of personnel in the production industry based on its hierarchical structure (organisational charts) were determined using Eq. (2). Second, with a channels lifespan of three years with discount rates of $8.75 \%$, the cost and benefit of adopting modern communication channels/media in the industry compared to the traditional use of messengers was evaluated using Eqns. (3-9). Third, the AHP technique was applied to find the utility values of affordability and usability of the channels using the cost and benefit outcomes as presented in Eqns. (10-19). Last, combinations of communication channels' effectiveness as related to productivity were assessed and compared monetarily and subjectively using a cost-benefit analysis and AHP techniques, respectively. Appendix A (IIII) shows a detailed analysis of the data using AHP technique. The information used in the AHP was obtained from industrial experts using interviews and questionnaires on their views about the various factors (attributes) under consideration. Table $2 \mathrm{a}$ shows the communication channels' final output weighting of the utility values for affordability (acquisition cost/overhead saving, development cost/productivity cost, and operation cost/maintenance savings), and usability (performance, availability, and quality) using AHP during which productivity and availability criteria were given the highest weighting.

\section{Results and Discussion}

The comparison of the overall cost, benefits, and the benefit-cost ratio is shown in Table $2 b$ as compared to messengers as a traditional 
Table 2a. Output weights of the channels' utility attributes using AHP.

\begin{tabular}{lcl}
\hline Affordability utility attributes & Weight $\left(w_{n}\right)$ & Values \\
\hline Acquisition costs/overhead savings & $w_{1}$ & 0.23 \\
Development costs/productivity costs & $w_{2}$ & 0.58 \\
Operations cost/maintenance savings & $w_{3}$ & 0.19 \\
& Total & 1.00 \\
Usable utility attributes & & \\
Performance & $w_{1}$ & 0.23 \\
Availability/reliability & $w_{2}$ & 0.58 \\
Quality & $w_{3}$ & 0.19 \\
& Total & 1.00 \\
\hline
\end{tabular}

Table $\mathbf{2 b}$. Comparison of discounted benefit-cost ratio (BCR).

\begin{tabular}{lllll}
\hline \multicolumn{5}{c}{ Relative value comparison } \\
\hline Channel type & $\begin{array}{l}\text { Discounted } \\
\text { cost }(\mathrm{N})\end{array}$ & $\begin{array}{l}\text { Discounted } \\
\text { benefit }(\mathrm{N})\end{array}$ & $\begin{array}{l}\text { Discounted } \\
\text { net }(\mathrm{N})\end{array}$ & $B C R$ \\
\hline Mobile phone & 3053881.89 & 13430040.63 & 10376158.74 & 4.39 \\
Intranet & 2056085.64 & 15615168.51 & 13559082.87 & 7.59 \\
$\begin{array}{l}\text { Fixed internet } \\
\text { Mobile }\end{array}$ & 3684105 & 14429658.34 & 10745553.34 & 3.91 \\
internet & 3931563.14 & 16837339.42 & 12905776.28 & 4.28 \\
PBX system & 2023185.74 & 12248106.76 & 10224921.02 & 6.05 \\
\hline BCR = benefit-cost ratio; PBX $=$ private branch exchange & &
\end{tabular}

Table 3. Corresponding utility values for various combinations of channels.

\begin{tabular}{lccc}
\hline Channel type & Performance & Availability & Quality \\
\hline Mobile phone & 0.06367 & 1.00000 & 0.00000 \\
Intranet & 0.25093 & 0.25093 & 0.25093 \\
Fixed internet & 0.06367 & 0.25093 & 0.25093 \\
Mobile internet & 0.06367 & 1.00000 & 0.25093 \\
PBX & 0.25093 & 0.25093 & 0.00000 \\
\hline PBX $=$ private branch exchange & &
\end{tabular}

communication channel. From the table, mobile internet contributed highest to the cost of production (N3931563.14) while the PBX phone system contribute the lowest to costs (N2023185.74). Management decisions based on minimum production cost contributions will most likely identify a PBX system as an optimal choice. Similarly, mobile internet contributed the highest benefits to production in terms of revenue generation (N16837339.42), while a PBX system contributed the lowest benefits (N12248106.76). Based on maximum benefits, the use of mobile internet would be the superior choice. However, the highest discounted net benefit (N13559082.87) was obtained through an intranet channel, and a PBX system was the lowest (N10224921.02). Therefore, the choice of an intranet channel was supportive of productivity of the industry at this level. Similarly, an evaluation based on a $\mathrm{BCR}$ indicated that intranet, having the highest BCR (7.59), would be the best channel for improved productivity. The corresponding utility values for the combinations of the channels are presented in Table 3. Performance-based utility results showed that intranet and PBX were better for productivity than a combination of mobile phones, fixed internet, and mobile internet with a higher probability of 0.25093 . Diverse results were obtained from utility of availability. In this case, the mobile phone and mobile internet were found to be better with a probability close to unity because of the usual network availability, than the combination of an intranet, fixed internet, and PBX system. When considering quality, only the intranet, fixed internet, and mobile internet were found to be 
promising for production sustainability in a situation dominated by moderate network quality.

The utility values of affordability and usability, and their overall utility are shown in Table 4. The overall utility of interaction channels showed that mobile phone networks have the best overall utility value of 0.59 . The high utility of mobile phones has resulted in its categorization of it as the best network among a combination of channels usable to enhance productivity. Based on the subjective results obtained from the developed system, availability was the leading factor which made the mobile phone and mobile internet networks the best candidates for productivity enhancement in industry (Table 3). However, mobile phones were the best channel to adopt (with 0.59 probability) according to an overall utility assessment (Table 4). Figure 2 indicated that mobile internet possessed the highest usability, followed by mobile phones, the intranet, fixed internet, and a PBX system.

\section{Conclusion}

Information management has a prominent role to play in effective operation in the manufacturing industry. Understanding the organizational structure of a company in terms of active interaction among personnel is paramount for effective evaluation of communication channels that, apart from cost savings, will enhance productivity. In this study, an efficient system model was developed to determine optimal personnel interaction strategies in the plastic production industry. In developing the model, interaction levels of the categories of the personnel in the production industry were obtained. A study of the cost and benefit of adopting modern communication channels/media in industry aside from traditional human messengers was carried out. AHP was applied to find the utility values of affordability and usability of the network channels. The outcomes from the application of the model to the plastic industry indicated that the mobile internet channel, in terms of a $B C R$, had the highest benefits while the $P B X$ had the lowest. The intranet channel had the highest overall $B C R$ while the mobile phone and mobile internet had the highest utility in terms of affordability and usability, respectively. The findings generally showed that intranet, mobile phones, and mobile internet were the best three productivityenhancing networks, and they could adequately replace traditional communication methods in industry. Further studies to investigate system robustness in response to problems associated with staff of different sizes and complexities are encouraged in the future. This is necessary to develop a generalized system, which can accommodate varying organizational complexities and attitudes associated with personnel.

Table 4. Utility values of communication channels.

\begin{tabular}{lccc}
\hline Channel type & Affordability & Usability & $\begin{array}{c}\text { Overall } \\
\text { utility values }\end{array}$ \\
\hline Mobile phone & 0.58 & 0.59 & 0.59 \\
Intranet & 0.27 & 0.25 & 0.26 \\
Fixed internet & 0.28 & 0.21 & 0.25 \\
Mobile internet & 0.35 & 0.64 & 0.50 \\
PBX & 0.45 & 0.07 & 0.26 \\
\hline PBX = private branch exchange & &
\end{tabular}

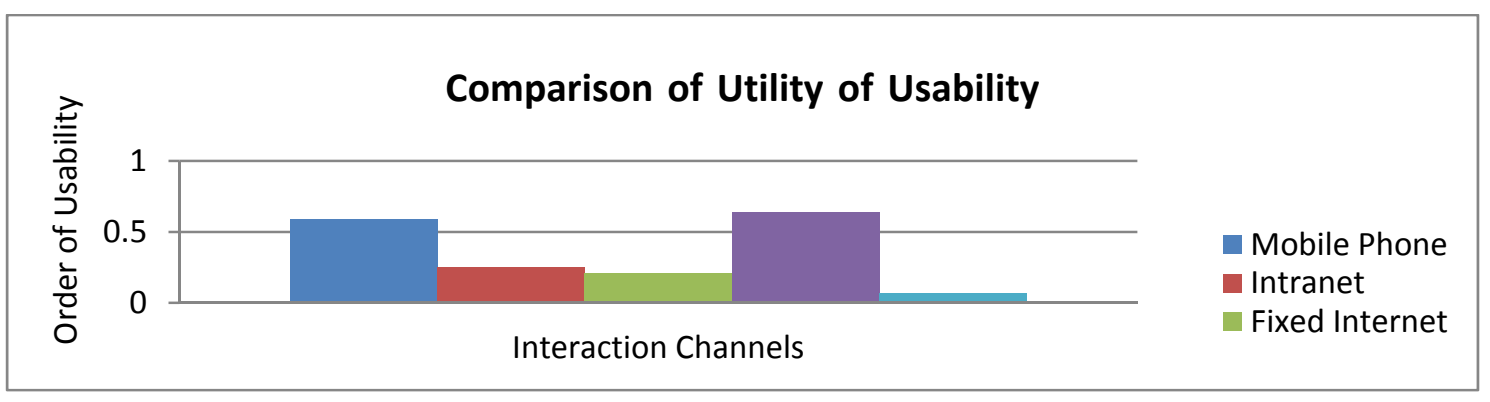

Figure 2. Comparison of utility of usability. 


\section{Acknowledgment}

The author acknowledges the Federal University of Technology, Akure, Nigeria, for providing the necessary facilities for the successful completion of this study. The management of the plastics production industry in Osogbo, Nigeria, is also acknowledged for releasing its data for this study.

\section{References}

Adams SM., Sarkis J, Liles DH (1995), A tool for the development of strategic performance metrics for enterprise activities. Proceedings of the Fourth Annual Industrial Engineering Research Conference, Institute of Industrial Engineers. Nashoille, TN.

Balschbach G, Klinke J, Jaehne B (1998), Multichannel shape from shading techniques for moving specular surfaces. Lecture Notes in Computer Science 1407: 170-184.

Bhattacharjee D (2007), A proposed cost-benefit analysis model for physical form analysis for a futuristic submarine decision support system. Unpublished MSc. Thesis, System Design and Management Program, Massachusetts Institute of Technology.

Biggiero L (1999), Complexity and organization in modern day. International Handbook of IT/S, Italian Conference on Systemics. Apogeo. Milan.

Cevasco J, Marmolejo RF (2013), The importance of studying prosody in the comprehension of spontaneous spoken discourse. Revista Latinoamericana de Psicologia 45(1): 21-33.

CIA World Factbook (2011), https://www.cia.gov / library / publications / the-world-factbook / geos.html Access on 27th August, 2011.

Drucker PF (2002), The discipline of innovation. Harvard Business Review 95-98.

Feital T, Kruger U, Dutra J, Pinto JC, Lima EL (2013), Modelling and performance monitoring of multivariate multimodal processes, AIChE Journal 59(5):1557-1569.

Finnie GR, Wittig GE, Petkov DI (1993), Prioritizing software development productivity factors using the analytic hierarchy process. Journal of Systems and Software 22(2): 129-139.
Froehle CM (2006), Service personnel, technology, and their interaction in influencing customer satisfaction. Decision Sciences Journal 37(1): 5-38.

Gurbaxani V, Plice R (2004), A model of network-centric organizations. Working Paper UCI CRITO Consortium, http:// www.crito.uci.edu/consortium Accessed 30th November, 2009.

Hurley S (2008), The shared circuits model (SCM): how control, mirroring, and simulation can enable imitation, deliberation, and mindreading. Behavioural and Brain Sciences 31(1): 1-22.

Jackson P, Skirrow P, Hare DJ (2012), Asperger through the looking glass: an exploratory study of self-understanding in people with Asperger's syndrome. Journal of Autism and Developmental Disorders 42(5): 697-706.

Jaques E (1998), Requisite organization, a tool system for effective managerial organization and managerial leadership for $21^{\text {st }}$ century. Cason Hall and Co Pub. North America, USA.

Kareem B (2014), Cost -benefit model for optimal selection of communication channels in manufacturing organisation. NED University Journal of Research-Applied Sciences XI(2): 1-13.

Kareem B (2015), Evaluation of failures in mechanical crankshafts of automobile based on expert opinion. Case Studies in Engineering Failure Analysis 3(1): 25-33.

Kleinbaum AM, Stuar TE, and Tushman ML (2008), Communication and coordination in a modern, complex organization. http:/ / www.hbswk.hbs.edu/item/5991.ht $\mathrm{ml}$ Accessed 30th November, 2009.

Kuboye BM., Alese BK Fajuyigbe O (2009), Congestion analysis on the Nigerian global system for mobile communications (GSM) network. The Pacific Journal of Science and Technology 10(1): 262-271.

Larkin TJ, Larkin S (2005), Communicating big change: using small communication $\left(2^{\text {nd }}\right.$ Edition). Larkin Communication Consulting.

Li C, Pickup D, Saunders T, Cosker D, Marshall D, Hall P, Willis P (2013), Water surface modelling from a single viewpoint video. IEEE Transactions on Visualization and Computer Graphics 19 (7): 1242-1251.

Lievrouw LA (2008), Communication. Microsoft Encarta 2009 [DVD]. Redmond, WA: Microsoft Corporation, 2008. 
Lu L, Yu X (2012), A multimedia teaching method research of animation production in China, ICCSE 2012 - Proceedings of 2012 7th International Conference on Computer Science and Education. 1495-1497.

Mackenzie KD (1978), Organizational structure. AHM Publishing Corporation. Ahmedabad, India.

NDB-Nigeria Data Bank (2007), Nigeria GSM statistic. December 2007.

Nohria N, Eccles R (1992), Face-to-face: making network organisations work. In: Nohria N. and R. Eccles (eds.) Networks and Organisations: Structure, Form and Action. Boston.

Nohria N, Ghoshal S (1997), The differentiated network. Organizing multinational corporations for value creation. JosseyBass, San Francisco.

Mtega WP, Msungu AC (2013), Using information and communication technologies for enhancing the accessibility of agricultural information for improved agricultural production in Tanzania. Electronic Journal of Information Systems in Developing Countries 56(1): 1-14.

Nagy M (2013), A multi-channel communication framework. Communications in Computer and Information Science 347: 72-88.

Nucci M, Grassi M, Piazza F (2013), Ontologybased device configuration and management for smart homes. Smart Innovation, Systems and Technologies 19: 301310

Nyambo B, Ligate E (2013), Smallholder information sources and communication pathways for cashew production and marketing in Tanzania: an ex-post study in Tandahimba and Lindi Rural Districts, Southern Tanzania. Journal of Agricultural Education and Extension 19 (1): 73-92.

Olokede SS (2009), Reliability analysis of fixed wireless networks in Nigeria. The Pacific Journal of Science and Technology 10(1): 251255.

Opperman SB (2013), Modernization and rural health in Mexico: The case of the Tepalcatepec Commission. Endeavour 37 (1): 47-55.
Payne AC, Chelsom JV, Reavill LRP (1996), Management for Engineers. John Wiley and Sons, England.

Saaty TL (1990), How to make a decision: the analytic hierarchy process. European Journal of Operational Research 48(1): 9-26.

Saaty TL (2008), Decision making with the analytic hierarchy process. International Journal of Services and Sciences 1(1): 83-98.

Shannon CE (1948), A mathematical theory of communication. The Bell System Technical Journal 27(6): 379-423.

Sooksumrarn P, Krairiksh M (2013), UHF wireless communication channel in a tree canopy. IEEE Antennas and Propagation Society, AP-S International Symposium (Digest) article no. 6393914: 311-314

Stohl C (1995), Organizational communicationconnectedness in action. Sage Publications London, New Delhi.

Urwick LF (1943), Personnel management in relation to factory organization. L. Urwick Institute of Labour Management, London.

Urwick LF (1974), The manager's span of control. The Academy of Management Journal 10(1): 349-354.

Vargas LG (1990), An overview of the analytic hierarchy process and its applications. European Journal of Operational Research 48(1): 2-8.

Wada S, Sasaoka N, Itoh Y, Okello J, Kobayashi M (2013), Speech enhancement based on bias free noise reconstruction method. ISPACS 2012 - IEEE International Symposium on Intelligent Signal Processing and Communications Systems, article no. 6473537: 479-484.

Yates JA, Orlikowski WJ, Okamura K (1999), Explicit and implicit structuring of genres in electronic communication: reinforcement and change of social interaction. Organization Science 10(4): 83-103.

Zhao Y, Xue X, Zhang T (2013), Receiverchannel based adaptive blind equalization approach for GPS dynamic multipath mitigation 2013. Chinese Journal of Aeronautics 26(2): 378-384. 


\section{Appendix A (I, II \& III): Utility and Performance Analysis}

\section{Determining the Utility of Affordability: The utility of Affordability-Individual Weights}

The analytical hierarchy process (AHP) was used to calculate the individual weights among the various attributes. For comparing two attributes, a scale of 1-5 was used to make comparisons proposed in the AHP.

Among the three attributes of affordability (acquisition, development, and operations), the ranking of the various attributes are assumed as follows: development is as important as operations; acquisition is much more important than development, and acquisition is moderately more important than operations.

The order of the three attributes is acquisition followed by development and operations. A $3 \times 3$ matrix is required for comparing three attributes. The $3 \times 3$ eigenvalue matrix for the preferences stated above takes the following form:

$$
\text { [A] } 3 \times 3=\left[\begin{array}{ccc}
1.0 & { }_{\mathrm{a}} 12 & { }^{\mathrm{a}} 13 \\
{ }_{\mathrm{a}} 21 & 1.0 & { }^{\mathrm{a}} 23 \\
{ }^{\mathrm{a}} 31 & { }^{\mathrm{a}} 32 & 1.0
\end{array}\right]
$$

Here, $\mathrm{a}_{12}$ refers to comparing acquisition over development. Similarly, $\mathrm{a}_{32}$ refers to comparing operations over development. Based on the preferences of the attributes, the pair-wise comparison of the attributes would be as follows:

$$
=\left[\begin{array}{ccc}
1.0 & 0.5 & 1.5 \\
2.0 & 1.0 & 3.0 \\
1.5 & 0.25 & 1.0
\end{array}\right]
$$

The normalized matrix is determined by dividing the values in each column by the sum of the column as follows:

$$
=\left[\begin{array}{lll}
0.15 & 0.29 & 0.23 \\
0.54 & 0.57 & 0.62 \\
0.27 & 0.14 & 0.15
\end{array}\right]
$$

Now, the eigenvector is formed as the average of each normalized row:

$$
{ }^{[w]} 3 \times 1=\left[\begin{array}{c}
w 1 \\
w 2 \\
w 3
\end{array}\right]=\left[\begin{array}{l}
0.23 \\
0.58 \\
0.19
\end{array}\right]
$$

Finally, the eigenvector is the weights of the three attributes using the AHP model where the weights of all the attributes add up to 1 . The different weights are as follows:

$$
\begin{array}{ll}
\text { Weight }_{\text {(acquisition costs/overhead savings) }} & =0.23 \\
\text { Weight }_{\text {(development cost/productivity increase) }} & =0.58 \\
\text { Weight }_{\text {(operations costs/maintenance savings) }} & =0.19
\end{array}
$$

These weights, along with the individual utilities calculated, are taken together for calculating the final utility using the additive utility function.

Utility of affordability - individual utility: 
Utility $\mathrm{j}(\mathrm{x})=(\mathrm{x}$ - worst value $) /($ best value - worst value $)$

$$
\begin{array}{ll}
\text { Utility }_{\text {mobile phone (Acquisition) }}=(2.62-1.08) /(331.23-1.08) & =0.00467 \\
\text { Utility } \left._{\text {mobile phone (Development) }}=(331.23-1.08)\right) /(331.23-1.08) & =1.00000 \\
\text { Utility }_{\text {mobile phone (Operations) }}=(1.15-1.08) /(331.23-1.08) & =0.00021 \\
\text { Utility }_{\text {intranet (Acquisition) }}=(2.33-1.08) /(331.23-1.08) & =0.00378 \\
\text { Utility }_{\text {intranet (Development })=(152.37-1.08) /(331.23-1.08)} & =0.45553 \\
\text { Utility }_{\text {intranet (Operations) }}=(10.83-1.08) /(331.23-1.08) & =0.02955 \\
\text { Utility }_{\text {fixed internet (Acquisition) }}=(1.15-1.08) /(331.23-1.08) & =0.00021 \\
\text { Utility }_{\text {fixed internet (Development) }}=(158.99-1.08) /(331.23-1.08) & =0.047869 \\
\text { Utility }_{\text {fixed internet (Operations) }}=(1.26-1.08) /(331.23-1.08) & =0.00055 \\
\text { Utility }_{\text {mobile internet (Acquisition) }}=(1.08-1.08) /(331.23-1.08) & =0.00000 \\
\text { Utility }_{\text {mobile internet (Development) }}=(198.73-1.08) /(331.23-1.08) & =0.59909 \\
\text { Utility }_{\text {mobile internet (Operations) }}=(3.05-1.08) /(331.23-1.08) & =0.00597 \\
\text { Utility }_{\text {pbx (Acquisition) }}=(2.03-1.08) /(331.23-1.08) & =0.00289 \\
\text { Utility }_{\text {pbx (Development) }}=(248.42-1.08) /(331.23-1.08) & =0.74969 \\
\text { Utility }_{\text {pbx (Operations) }}=(24.24-1.08) /(331.23-1.08) & =0.07019
\end{array}
$$

These are the individual utility values for the various attributes categorized under various interaction channels. The next step is to calculate the individual weights.

Utility of affordability - additive utility:

The weighted utility function for the three attributes of acquisition, development, and operations is represented by the equation:

Utility $j_{\text {(Acquisition, Development, Operations })}=$ Weight $_{\text {(Acquisitions) }} *$ Utility $_{\text {(Acquisitions) }}+$ Weight (Development) $^{*}$

Utility $j_{\text {(Development) }}+$ Weight (Operations) ${ }^{*}$ Utility $_{j}$ (Operations)

Here subscript $\mathrm{j}$ represents the various available options: mobile phone, intranet, fixed internet, mobile internet, and PBX systems. Based on this additive utility function, the utility of the various options is as follows:

$$
\begin{aligned}
& \text { Utility mobile phone (acquisition, development, operations) }=0.23 * 0.00467+0.58 * 1+0.19 * 0.00021 \\
& =0.5811141 \\
& \text { Utility }_{\text {intranet }} \text { (acquisition, development, operations) }=0.23 * 0.00378+0.58 * 0.4553+0.19 * \\
& 0.02955=0.2705579 \\
& \text { Utility fixed internet (acquisition, development, operations) }=0.23 * 0.00021+0.58 * 0.47869+0.19 * \\
& 0.00055=0.277793 \\
& \text { Utility mobile internet (acquisition, development, operations) }=0.23 * 0.0000+0.58 * 0.59909+0.19 * \\
& 0.00597=0.3485563 \\
& \text { Utility } \left._{\text {Рвх }} \text { (acquisition, development, operations }\right)=0.23 * 0.00289+0.58 * 0.74969+0.19 * 0.07019 \\
& =0.4488211
\end{aligned}
$$

Therefore, the CBRs obtained earlier were converted to equivalent utility values. The utility values of affordability for the various display options are as follows:

$$
\begin{array}{ll}
\text { Utility mobile phone (affordability) } & =0.58 \\
\text { Utility intranet (affordability) } & =0.27 \\
\text { Utility fixed internet (affordability) } & =0.28
\end{array}
$$




$$
\begin{array}{ll}
\text { Utility mobile internet (affordability) } & =0.35 \\
\text { Utility PBX (affordability) } & =0.45
\end{array}
$$

\section{Utility of Usability}

Utility of usability for the channels of interaction were obtained in similar way as that of

\begin{tabular}{|c|c|}
\hline Utility Mobile Phone (Usability) & $=0.59$ \\
\hline Utility Intranet $_{\text {(Usability) }}$ & $=0.25$ \\
\hline Utility Fixed Internet (Usability) & $=0.21$ \\
\hline Utility Mobile Internet (Usability) & 4 \\
\hline Utility рвх (Usability) & \\
\hline
\end{tabular}
affordability. The outcomes are as follows:

\section{Overall Utility Value}

In this paper, it was assumed that affordability is equally important to usability. Since both the attributes are equally important, the AHP model will generate the same weight for both attributes. Therefore, weight (affordability) $=0.5$, and weight (usability) $=0.5$. Using the additive utility function, the overall utility values are as follows:

$$
\begin{array}{ll}
\text { Overall utility Mobile Phone (affordability, usability) } & =0.5 * 0.58+0.5 * 0.59=0.585 \\
\text { Overall utility Intranet (affordability, usability) } & =0.5 * 0.27+0.5 * 0.25=0.26 \\
\text { Overall utility Fixed Internet (affordability, usability) } & =0.5 * 0.28+0.5 * 0.21=0.245 \\
\text { Overall utility Mobile Internet (affordability, usability) } & =0.5 * 0.35+0.5 * 0.64=0.50 \\
\text { Overall utility }{ }_{P B X} \text { (affordability, usability) } & =0.5 * 0.45+0.5 * 0.07=0.26
\end{array}
$$

Therefore, the order of utility is as follows: mobile phone, mobile internet, intranet, PBX, and fixed internet. 